\title{
Emetine exhibits anticancer activity in breast cancer cells as an antagonist of Wnt/ $\beta$-catenin signaling
}

\author{
QI SUN, QIUXIA FU, SHIYUE LI, JUNJUN LI, SHANSHAN LIU, \\ ZHONGYUAN WANG, ZIJIE SU, JIAXING SONG and DESHENG LU
}

\begin{abstract}
Guangdong Key Laboratory for Genome Stability and Disease Prevention, Carson International Cancer Center, Department of Pharmacology, Shenzhen University Health Science Center, Shenzhen, Guangdong 518060, P.R. China
\end{abstract}

Received November 19, 2018; Accepted June 28, 2019

DOI: 10.3892 /or.2019.7290

\begin{abstract}
Emetine, an amoebicidal drug, exerts potent anticancer activity against various solid tumors, however, the underlying molecular mechanism remains unclear. In the present study, the effects of emetine were investigated on various proteins involved in the $\mathrm{Wnt} / \beta$-catenin signaling pathway, which has been linked to various human cancers. It was revealed that emetine blocked Wnt/ $\beta$-catenin signaling by targeting components of this pathway, including the low-density lipoprotein-receptor-related protein 6 (LRP6) and disheveled (DVL). Moreover, nanomolar concentrations of emetine decreased phosphorylation of these proteins and suppressed the expression of Wnt target genes, including fibronectin, frizzled-7 (Fzd7), c-Myc, Nanog and CD133 in MDA-MB-231 and MDA-MB-468 breast cancer cells. Additionally, emetine treatment induced apoptosis and suppressed the viability, migration, invasion, and sphere formation of breast cancer cells. Collectively the present results indicated that emetine antagonizes $\mathrm{Wnt} / \beta$-catenin signaling, providing insight into the molecular mechanism underlying the anticancer activity of emetine.
\end{abstract}

Correspondence to: Professor Desheng Lu, Guangdong Key Laboratory for Genome Stability and Disease Prevention, Carson International Cancer Center, Department of Pharmacology, Shenzhen University Health Science Center, Shenzhen, Guangdong 518060, P.R. China

E-mail: delu@szu.edu.cn

Abbreviations: APC, adenomatosis polyposis coli; CK1, casein kinase 1; CSCs, cancer stem cells; DMEM, Dulbecco's modified Eagle's medium; DMSO, dimethyl sulfoxide; DVL, dishevelled; EGF, epidermal growth factor; EMT, epithelial-mesenchymal transition; FBS, fetal bovine serum; FGF, fibroblast growth factor; Fzd, frizzled; GSK3 $\beta$, glycogen synthase kinase-3 $\beta$; LRP5/6, low-density lipoprotein receptor-related protein5/6; PVDF, polyvinylidene difluoride; SDS-PAGE, sodium dodecyl sulfate-polyacrylamide gel electrophoresis

Key words: natural alkaloid, LRP6, DVL2, Wnt signaling, breast tumor

\section{Introduction}

The Wnt/ $\beta$-catenin signaling pathway plays critical roles in embryonic development and tissue homeostasis, and aberrant Wnt signaling has been implicated in the pathogenesis of many different human cancers, including breast cancers (1-4). Therefore, this signaling pathway represents a target for the development of anticancer therapeutics. Wnt $/ \beta$-catenin signaling involves multiple proteins and binding events. It is initiated by binding of Wnt ligands to frizzled receptor (Fzd) as well as the co-receptor low-density lipoprotein receptor-related protein 5/6 (LRP5/6). This binding, results in activation of Wnt signaling, permitting additional binding of dishevelled (DVL), which triggers phosphorylation of LRP5/6 at one or more cytoplasmic motifs. Subsequently, phosphorylated LRP5/6 enhances the interaction between DVL and Axin, which destabilizes the $\beta$-catenin destruction complex composed of Axin, adenomatous polyposis coli (APC), casein kinase 1 (CK1), and glycogen synthase kinase $3 \beta$ (GSK-3 $\beta$ ) (5). The destruction complex can phosphorylate $\beta$-catenin, which is the central mediator of canonical Wnt signaling through GSK $3 \beta$, and thereby induce the degradation of $\beta$-catenin by the ubiquitin-proteasome pathway (6). Disaggregation of the destruction complex results in inhibition of $\beta$-catenin phosphorylation, which leads to cytoplasmic $\beta$-catenin accumulation. Upon reaching a sufficiently high cytoplasmic concentration, $\beta$-catenin translocates to the nucleus where it promotes expression of Wnt target genes, such as CD44, cyclin D1, c-Myc, survivin and fibronectin (7-9).

Emetine, a natural alkaloid isolated from Psychotria ipecacuanha, has been revealed to inhibit the synthesis of various biomolecules $(10,11)$ and used to treat amoebiasis since the early 1900s (12). Phase I and II clinical trials evaluating the anticancer efficacy of emetine were conducted by the National Cancer Institute in the mid-1970s (13-16). However, these clinical studies did not lead to the clinical application of emetine as they revealed only marginal efficacy and some adverse side effects, such as cardiac damage. In recent years, derivatives of emetine have been synthesized and reported to offer better efficacy against cancer cells along with less toxicity to normal cells $(17,18)$. Moreover, various studies have demonstrated a potent cytotoxic activity of emetine and its biological targets in a variety of human carcinoma cell lines (19-24). Emetine 
has been investigated in combination with other agents for evaluation of their synergistic antitumor effects toward the goal of achieving effective treatment with a reduced dose and fewer side effects $(25,26)$. Specifically, Visnyei et al identified emetine as an inhibitor of glioblastoma stem cells using a molecular screening system (27). Another study demonstrated that emetine inhibits the hedgehog signaling pathway by binding to hedgehog, smoothened and Gli protein, which have been implicated in the biology of cancer stem cells (CSCs) (28). However, the molecular mechanism by which emetine targets CSCs remains unclear, and such knowledge could facilitate the potential application of emetine and its structural modifications in cancer chemotherapy. Therefore, in the present study, the effects of emetine on Wnt signaling were investigated in multiple breast cancer cell lines. The present results revealed emetine as a novel $\mathrm{Wnt} / \beta$-catenin signaling antagonist that suppresses the phosphorylation of LRP6 and dishevelled-2 (DVL2).

\section{Materials and methods}

Reagents and plasmids. Emetine was purchased from Sigma-Aldrich; Merck KGaA. Emetine was dissolved in dimethyl sulfoxide (DMSO) for preparation of a stock solution at a concentration of $10 \mathrm{mM}$. For use with cells, the stock solution was diluted with the cell-specific media, and the final DMSO concentration was $<0.1 \%$. The SuperTOPFlash reporter plasmid was a kind gift from Dr Karl Willert (University of California at San Diego, San Diego, CA, USA). The expression plasmids for Wnt1, LRP6, CK1, DVL2, $\beta$-catenin, and $\beta$-galactosidase $(\beta$-gal) have been previously described $(29,30)$.

Cell culture. 293T, MDA-MB-231, MDA-MB-468, Hs578T, and MCF10A cells were obtained from the American Type Culture Collection (ATCC). 293T and Hs578T cells were cultured in Dulbecco's Modified Eagle's Medium (DMEM) (Gibco; Invitrogen; Thermo Fisher Scientific, Inc.) supplemented with $10 \%$ fetal bovine serum (FBS) and $1 \%$ penicillin-streptomycin in $5 \% \mathrm{CO}_{2}$ at $37^{\circ} \mathrm{C}$. MDA-MB-231 and MDA-MB-468 cells were grown in Leibovitz's L-15 medium (Gibco; Invitrogen; Thermo Fisher Scientific, Inc.) supplemented with $10 \% \mathrm{FBS}$ and $1 \%$ penicillin-streptomycin at $37^{\circ} \mathrm{C}$ in a humidified incubator without $\mathrm{CO}_{2}$. MCF10A cells were cultured in DMEM/Ham's F-12 (Gibco; Invitrogen; Thermo Fisher Scientific, Inc.) supplemented with $100 \mathrm{ng} / \mathrm{ml}$ cholera toxin, $20 \mathrm{ng} / \mathrm{ml}$ epidermal growth factor (EGF), $0.01 \mathrm{mg} / \mathrm{ml}$ insulin, $500 \mathrm{ng} / \mathrm{ml}$ hydrocortisone, and $5 \%$ chelex-treated horse serum. All of the growth factors were purchased from Sigma-Aldrich (Merck KGaA).

Luciferase reporter gene assay. 293T cells were transfected with reporter plasmid $(0.25 \mu \mathrm{g})$, control plasmid pCMX bgal (50 ng), and the indicated expression plasmids (50-200 ng) using Lipofectamine 2000 (Invitrogen; Thermo Fisher Scientific, Inc.) according to the manufacturer's instructions. After transfection for $24 \mathrm{~h}$, the cells were treated with emetine at concentrations of 0 (control), 6.25, 12.5, 25, 50 or $100 \mathrm{nM}$ for the indicated culture time-points. Luciferase assays were performed using a luciferase assay kit (Promega Corp.) and the luciferase activity was normalized to $\beta$-gal activity.
Immunoblot analyses. Cells were harvested and sonicated in lysis buffer (20 mM Tris- $\mathrm{HCl}$ pH 7.4, $150 \mathrm{mM} \mathrm{NaCl}, 1 \mathrm{mM}$ EDTA, $1 \mathrm{mM}$ EGTA, 1\% Triton X-100, $2.5 \mathrm{mM}$ sodium pyrophosphate, $1 \mathrm{mM} \beta$-glycerol phosphate, $1 \mathrm{mM}$ sodium orthovanadate, $2 \mu \mathrm{g} / \mathrm{ml}$ leupeptin and $1 \mathrm{mM}$ PMSF) containing the protease inhibitor phenylmethylsulfonyl fluoride, and protein concentrations were determined using a BCA protein assay kit (Cell Signaling Technology, Inc.). Equal amount of proteins $(40 \mu \mathrm{g})$ were loaded in a $8 \%$ sodium dodecyl sulfate (SDS)-polyacrylamide gel, and transferred to polyvinylidene difluoride (PVDF) membranes for immunoblotting with anti-phospho LRP6 (Ser1490) (dilution 1:1,000; cat. no. 2560s), anti-LRP6 (dilution 1:1,000; cat. no. 2568L), anti-DVL2 (dilution 1:1,000; cat.no.3216s), anti-non-phospho (active) $\beta$-catenin (dilution 1:2,000; cat. no. 8814s; all from Cell Signaling Technology, Inc.), and anti- $\beta$-catenin (dilution 1:2,000; cat. no. sc-7963; Santa Cruz Biotechnology, Inc.), anti- $\beta$-actin (dilution 1:5,000; cat. no. HC-201; TransGen Biotech). After transferring, the PVDF membranes were blocking using 5\% non-fat powdered milk (cat. no. A600669-0250; Sangon Biotech Co., Ltd.) at room temperature for $1 \mathrm{~h}$. Then the PVDF membranes were incubated with HRP conjugated goat anti-mouse (dilution 1:10,000; cat. no. A16066; Thermo Fisher Scientific, Inc.) or anti-rabbit (dilution 1:10,000; cat. no. A16096; Thermo Fisher Scientific, Inc.) IgG for $1 \mathrm{~h}$ at room temperature. After incubated with ECL Plus Western Blotting Substrate (cat. no. 32132; Thermo Fisher Scientific, Inc.), the immunoblots were developed by either X-ray film (Kodak) or Chemiluminescent Imaging System (cat. no. 5200; Tanon). Densitometric analysis was carried out using the Image 1.8 .0 Analysis Software (National Institutes of Health), and the quantification results were normalized to the loading control.

Real-time polymerase chain reaction (PCR) analyses. Total RNA was isolated using RNAiso Plus (Takara Bio, Inc.) and reverse-transcribed into cDNA using the Primescript RT reagent kit (Takara Bio, Inc.) according to the manufacturer's instructions $\left(37^{\circ} \mathrm{C}, 15 \mathrm{~min} ; 85^{\circ} \mathrm{C}, 5 \mathrm{sec}\right)$. Prepared cDNA was then used for the quantitative PCR analysis $\left(95^{\circ} \mathrm{C}, 5 \mathrm{~min} ; 95^{\circ} \mathrm{C}\right.$, $\left.15 \mathrm{sec}, 60^{\circ} \mathrm{C}, 1 \mathrm{~min}\right)$ using FastStart Universal SYBR-Green Master (Roche Applied Science). The primers used were as follows: Fibronectin sense, 5'-ACCTACGGATGACTCGTG CTTT-3' and antisense, 5'-TTCAGACATTCGTTCCCACTC A-3'; frizzled-7 (Fzd7) sense, 5'-CAACGGCCTGATGTACTT TAAGG-3' and antisense, 5'-CATGTCCACCAGGTAGGT GAGA-3'; c-Myc sense, GCCACGTCTCCACACATCAG and antisense, TCTTGGCAGCAGGATAGTCCTT; CD133 sense, 5'-AGTCGGAAACTGGCAGATAGC-3' and antisense, 5'-GGTAGTGTTGTACTGGGCCAAT-3'; and Nanog sense, 5'-TTTGTGGGCCTGAAGAAAACT-3' and antisense, 5'-AGGGCTGTCCTGAATAAGCAG-3'.

Lentiviral shRNA. The sequences of $\beta$-catenin shRNAs were as follows: sh $\beta$-cat\#1: CCGGTTGTTATCAGAGGACTA AATACTCGAGTATTTAGTCCTCTGATAACAATTTTTG; sh $\beta$-cat\#2: CCGGAGGTGCTATCTGTCTGCTCTACTCGA GTAGAGCAGACAGATAGCACCTTTTTT. For infection with lentivirus, the cells were cultured with lentiviral solution for $24 \mathrm{~h}$ in the presence of $5 \mu \mathrm{g} / \mathrm{ml}$ Polybrene (Sigma-Aldrich; Merck KGaA). 
Cell viability assay. MDA-MB-231 and MDA-MB-468 cells were seeded at $1 \times 10^{4}$ cells/well in 96-well plates and allowed to incubate overnight. The cells were treated with emetine at concentrations of 0 (control), 12.5, 25, 50, 10 and $200 \mathrm{nM}$ for $48 \mathrm{~h}$. MTT reagent ( $5 \mathrm{mg} / \mathrm{ml} ; 20 \mu \mathrm{l} /$ well) was added and incubated for another $4 \mathrm{~h}$. The formazan crystals were dissolved in $150 \mu \mathrm{l} \mathrm{DMSO}$, and the absorbance of the formazan solution was measured at $570 \mathrm{~nm}$.

Apoptosis assay. After treatment with emetine (0-100 nM) for $24 \mathrm{~h}$, MDA-MB-231, MDA-MB-468, and MCF10A cells were collected and incubated with Annexin V-fluorescein isothiocyanate (FITC) and propidium iodide (PI) solutions (TransGen Biotech Co., Ltd.) according to the manufacturer's protocol. A FACSCalibur ${ }^{\mathrm{TM}}$ (BD Biosciences) fluorescence-activated cell-sorting (FACS) instrument was used for quantitative fluorescence sorting, and FlowJo v10.0.8 (Tree Star, Inc.) was used for subsequent analysis.

Scratch assay. MDA-MB-231 cells were cultured in a 24-well plate, and a 200- $\mu 1$ sterile pipette tip was passed through the cell monolayer to create a wound gap. Then, the cells were incubated with DMSO or 50 or $100 \mathrm{nM}$ emetine for $24 \mathrm{~h}$. Micrographs of the scratched areas were captured using an Olympus CKX53 microscope (Olympus Corp.).

Transwell assay. Cell migration and invasion were assessed using Transwell assays as previously described (31). Briefly, $2 \times 10^{5}$ cells suspended in serum-free medium were seeded in 24-well Transwell chambers with $8-\mu \mathrm{m}$ pore membranes. Emetine at 50 or $100 \mathrm{nM}$ was added to the top chamber, and DMEM containing 20\% FBS was added to the lower chamber as a chemoattractant. After $12 \mathrm{~h}$ of incubation, the cells on the upper surface of the membrane were wiped away, and the cells that had migrated to the lower surface of the membrane were stained with $0.1 \%$ crystal violet and photographed under a light microscope. For the invasion assay, the Transwell chambers were coated with Matrigel (Corning Life Sciences). For quantitative analysis, 33\% acetic acid was used to elute the stained cells, and the absorbance of the resultant solutions was detected at $570 \mathrm{~nm}$.

Sphere formation assay. Hs578T cells were seeded at 250 cells/well in DMEM medium [2\% B-27, $10 \mathrm{ng} / \mathrm{ml}$ EGF, $10 \mathrm{ng} / \mathrm{ml}$ fibroblast growth factor (FGF), and $10 \mu \mathrm{g} / \mathrm{ml}$ insulin] containing emetine (50 or $100 \mathrm{nM}$ ) in a 24-well Ultra-Low Attachment plate (Corning Inc.). All of the growth factors were purchased from Sigma-Aldrich (Merck KGaA). After 10 days in culture, spheres with a diameter greater than $50 \mu \mathrm{m}$ were counted, and representative fields were photographed under a light microscope. Each treatment was applied to three replicates.

Statistical analyses. Statistical analyses were performed using GraphPad Prism software (v5.0; GraphPad Software). The normal probability plot was used to examine data distributions. A Student's t-test was applied when the data exhibited normal distribution. The data were analyzed by Student's t-test or one-way analysis of variance (ANOVA) followed by Dunnett's t-test. A P-value $<0.05$ was considered to indicate a statistically significant difference. Data are presented as the mean \pm standard deviation (SD), and are derived from at least three independent assays, unless specified otherwise.

\section{Results}

Emetine suppresses Wnt/ $\beta$-catenin signaling. The cell-based TOPFlash reporter system was used for an initial screen of Food and Drug Administration (FDA)-approved drug libraries. Emetine (Fig. 1A) was identified as a potential inhibitor of Wnt/ $\beta$-catenin signaling. To assess the effect of emetine on Wnt signaling, 293T cells were transfected with a SuperTOPFlash reporter plasmid together with Wnt1, LRP6, Wnt1/LRP6, DVL2, or $\beta$-catenin expression plasmids (Fig. 1B-F). Treatment with 6.25-100 nM emetine effectively inhibited transcription of the SuperTOPFlash reporter activated by Wnt1 (Fig. 1B), LRP6 (Fig. 1C), Wnt1/LRP6 (Fig. 1D) and DVL2 (Fig. 1E) compared to 0 -nm treated group, while emetine had little effect on $\beta$-catenin-induced reporter activity (Fig. 1F). These results indicated that emetine may target upstream components of Wnt/ $\beta$-catenin signaling. In control experiments, Wnt inhibiting concentrations of emetine had no effect on the luciferase activity of an activator protein 1 (AP-1) reporter gene (Fig. 1G) or a nuclear factor of activated T cells (NFAT) reporter gene (Fig. 1H).

Emetine affects different components of the Wnt/ $\beta$-catenin signaling cascade. To further investigate the mechanism of the effect of emetine on the Wnt pathway, 293T cells were transfected with a Wnt1 expression plasmid. Overexpression of Wnt1 resulted in enhanced levels of phosphorylated LRP6, total LRP6, DVL2, activated $\beta$-catenin and cytosolic $\beta$-catenin (Fig. 2). Treatment with nanomolar concentrations of emetine significantly decreased the expression levels of phosphorylated LRP6, total LRP6, phosphorylated DVL2, active $\beta$-catenin and cytosolic $\beta$-catenin (Fig. 2). Notably, the extent of reduction in total and phosphorylated LRP6 was similar upon emetine treatment, suggesting that emetine may downregulate LRP6 expression, but not its phosphorylation. These findings indicated that emetine inhibits $\mathrm{Wnt} / \beta$-catenin signaling by targeting LPR6 and DVL2.

Emetine suppresses Wnt/ $\beta$-catenin signaling in breast cancer cells. The effect of emetine on $\mathrm{Wnt} / \beta$-catenin signaling was next assessed in the MDA-MB-231 and MDA-MB-468 breast cancer cell lines. Treatment with emetine decreased the levels of phosphorylated LRP6, total LRP6, phosphorylated and unphosphorylated DVL2, active $\beta$-catenin levels and cytosolic $\beta$-catenin in both cell lines (Fig. 3A and B). These results revealed that emetine suppressed $\mathrm{Wnt} / \beta$-catenin signaling in breast cancer cells.

Emetine downregulates the expression of Wnt target genes in breast cancer cells. To further evaluate the inhibitory effect of emetine on Wnt signaling in breast cancer cells, real-time PCR was performed to detect the mRNA expression of several Wnt target genes, including fibronectin, Fzd7, c-Myc, CD133 and Nanog. In MDA-MB-231 and MDA-MB-468 cells, emetine dose-dependently downregulated the transcription of fibronectin, Fzd7, c-Myc, CD133 and Nanog (Fig. 4). These results 
A<smiles>CC[C@H]1CN2CCc3cc(OC)c(OC)cc3[C@H]2C[C@H]1C[C@H]1NCCc2cc(OC)c(OC)cc21</smiles>

C

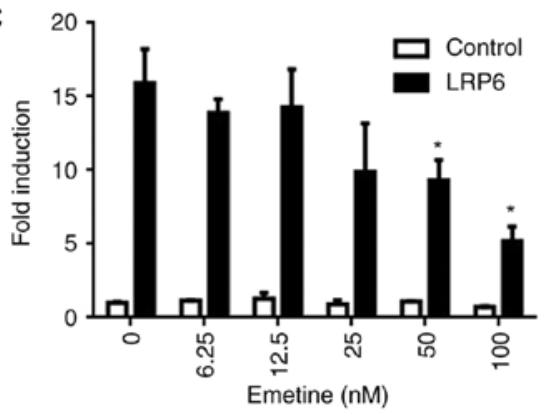

$\mathrm{E}$
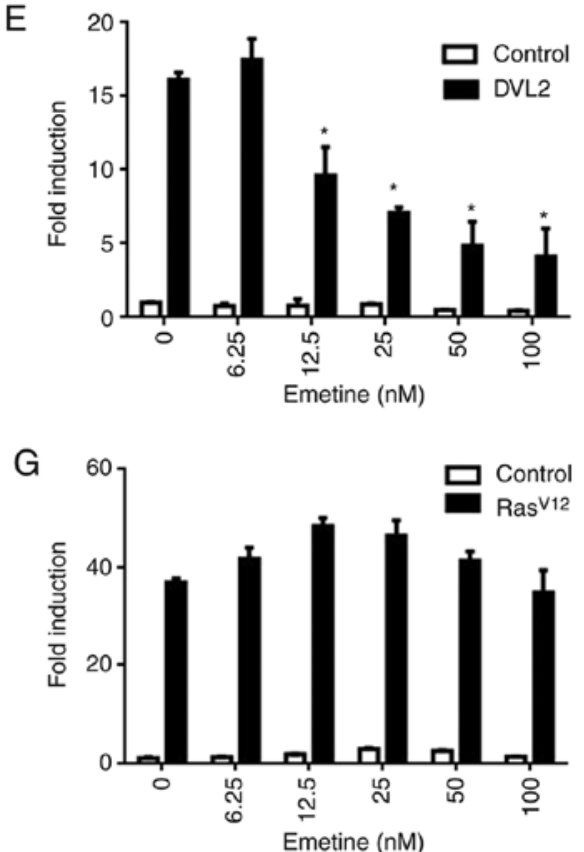
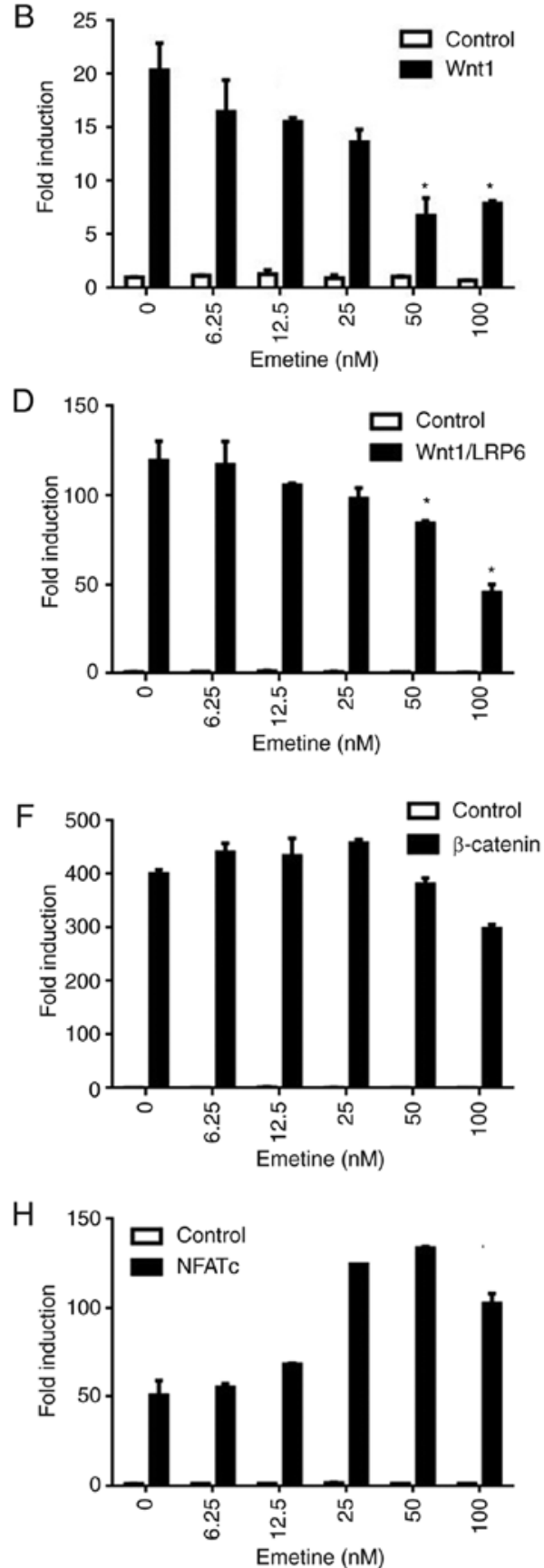

Figure 1. Emetine suppresses Wnt/ $\beta$-catenin signaling. (A) Chemical structural formula of emetine. (B-F) SuperTOPFlash reporter gene with empty vector or expression vectors encoding (B) Wnt1; (C) LRP6; (D) Wnt1 and LRP6; (E) dishevelled-2 (DVL2); and (F) $\beta$-catenin was used to transfect 293T cells before treatment with vehicle control (DMSO) or emetine $(6.25,12.5,25,50$ or $100 \mathrm{nM})$ for $24 \mathrm{~h}$. Luciferase activity was normalized to $\beta$-gal activity. 293T cells were transfected with (G) AP-1-Luc reporter along with control vector or a constitutively active Ras ${ }^{\text {v12 }}$ expression plasmid, and (H) NFAT-Luc reporter together with control vector or NFATc expression plasmid. Data are the average values from three independent experiments performed in duplicate $\left({ }^{*} \mathrm{P}<0.05\right)$. LRP6, low-density lipoprotein-receptor-related protein 6; AP-1, activator protein 1; NFAT, nuclear factor of activated T cells.

further confirmed the suppression of Wnt signaling in breast cancer cells treated with emetine.

Emetine inhibits the viability, migration and invasion of breast cancer cells while inducing apoptosis. An MTT assay was employed to examine the effect of emetine on the viability of breast cancer cells. The results revealed that treatment with emetine selectively reduced the viability of breast cancer MDA-MB-231 and MDA-MB-468 cells, but had little effect on MCF10A human mammary epithelial cells (Fig. 5A). The effect of emetine on apoptosis was then assessed among breast cancer cells. Evaluation of apoptosis among MDA-MB-231 and MDA-MB-468 cells after treatment with increasing concentrations of emetine $(0,25,50$ or $100 \mathrm{nM})$ for $24 \mathrm{~h}$, revealed that emetine selectively induced apoptotic cell death in both breast cancer cell lines compared to MCF10A cells (Fig. 5B).

Considering the important role of the Wnt pathway in cancer cell migration and invasion, the effects of emetine on 


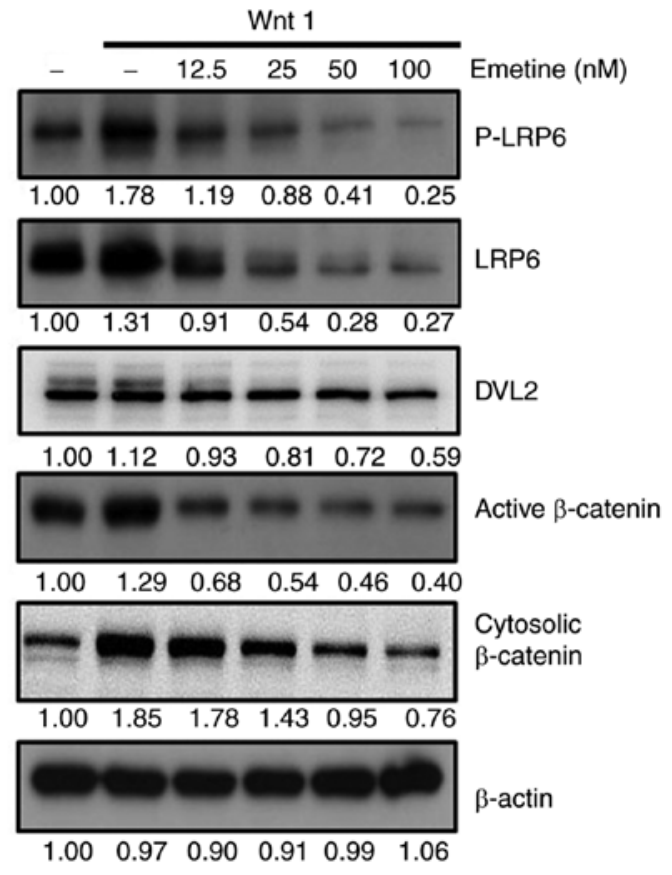

Figure 2. Emetine suppresses Wnt/ $\beta$-catenin signaling in $293 \mathrm{~T}$ cells. After transfection of $293 \mathrm{~T}$ cells with Wnt1 expression vector, the cells were treated with emetine at the indicated concentrations for $24 \mathrm{~h}$, and the expression levels of phosphorylated LRP6, total LRP6, DVL2, active $\beta$-catenin and total $\beta$-catenin were determined by western blotting. Phosphorylated DVL2 exhibited slower mobility on SDS/PAGE. Western blots were quantitated by densitometry and normalized by the densities of corresponding $\beta$-actin band.

the migratory and invasive activities of breast cancer cells were investigated. Results of an in vitro scratch assay revealed that emetine treatment suppressed the migration of MDA-MB231 breast cancer cells (Fig. 5C). The inhibitory effects of emetine on the migration of MDA-MB-231 and MDA-MB468 cells were further confirmed by Transwell migration assays (Fig. 5D and E). Using Matrigel-coated chambers, the Transwell assays were repeated to assess the effect of emetine on invasion by MDA-MB-231 and MDA-MB-468 cells. Treatment with emetine significantly reduced the numbers of cells that penetrated the membranes to reach the bottom wells compared with the vehicle control (Fig. 5F and G). Collectively, these results demonstrated that emetine suppressed the migratory and invasive abilities of breast cancer cells in vitro.

Emetine-induced reduction of cell viability is abrogated by shRNA-mediated silencing of $\beta$-catenin. To determine the effect of emetine on cells in which Wnt/ $\beta$-catenin signaling was already inhibited, lentivirus-mediated shRNAs were used to suppress the expression of $\beta$-catenin, a central mediator of the canonical Wnt/ $\beta$-catenin signaling pathway. The emetine-induced reductions in the viability of MDA-MB-231 cells (Fig. 6A and B) and MDA-MB-468 cells (Fig. 6C and D) were decreased after shRNA-mediated silencing of $\beta$-catenin. These data indicated that the cytotoxicity of emetine in breast cancer cells was mediated at least partly through the Wnt/ $\beta$-catenin signaling pathway.

Emetine blocks the stemness of breast cancer cells. Wnt/ $\beta$-catenin signaling plays a crucial role in the survival and maintenance of CSCs. A sphere formation assay was performed to examine the effect of emetine on the stemness of breast cancer cells. The breast cancer Hs578T cells were treated with emetine at 50 and $100 \mathrm{nM}$ for 10 days. As revealed in Fig. 7, treatment with emetine significantly decreased the number and size of tumor spheres. In addition, the mRNA expression levels of stemness marker genes (CD133 and Nanog) in breast cancer cells were downregulated upon emetine treatment (Fig. 4D and E).

\section{Discussion}

While the exact molecular mechanisms responsible for the effective antitumor activity of emetine remained unclear, previous research demonstrated that emetine can induce apoptosis through prevention of protein biosynthesis (21), DNA interaction (32) and increasing of pro-apoptotic factors $(26,33)$. This compound was also reported to reduce activation of hypoxia-induced factor-1 $\alpha$ (HIF-1 $\alpha$ ) in breast tumor cells (34). The results of the present study revealed that emetine is a novel inhibitor of the Wnt signaling pathway. In the present experiments, emetine reduced phosphorylation of LRP6 and DVL2 and inhibited the expression of Wnt target genes in multiple lines of breast cancer cells. Together our results illustrated a novel mechanism for the antitumor activity of emetine.

Aberrant activation of the Wnt/ $\beta$-catenin pathway has been implicated in the development of breast cancers (4), and primary cells from breast tumors as well as breast cancer cell lines were revealed to express several Wnt ligands and Fzd receptors $(35,36)$. Previous studies also demonstrated that LRP6 expression is upregulated in human breast cancer cells (37). Moreover, upregulation of DVL and phosphorylated DVL proteins has been revealed in several breast tumor cell lines $(38,39)$. In the present study, it was revealed that emetine decreased the phosphorylation of LRP6 and DVL2 as well as the activation of $\beta$-catenin in breast cancer cells, which resulted in effective inhibition of Wnt signaling. Notably, the inhibitory effect of emetine on viability of breast cancer cells were abolished in $\beta$-catenin-knockdown cells (Fig. 6). Additionally, the effects of emetine on Wnt signaling occurred at concentrations comparable to those required for inhibiting viability, migration and invasion, and inducing apoptosis in breast cancer cells. These results indicated that the antitumor activity of emetine was associated with its inhibitory effects on the Wnt signaling pathway.

CSCs have been defined as tumor-initiating cells that play critical roles in tumor development, recurrence and treatment resistance (40). The $\mathrm{Wnt} / \beta$-catenin pathway is recognized to be important in the regulation of CSC biology (41), and thus, blocking the $\mathrm{Wnt} / \beta$-catenin pathway could potentially eliminate CSC populations, resulting in complete cure of a cancer. In support of this hypothesis, one study revealed that emetine inhibits the stemness of glioblastoma stem cells (27). Several Wnt target genes, including Nanog and CD133, have been established as CSC markers (42-44). In the present study, it was observed that the expression of stemness marker genes Nanog and CD133 was reduced in breast cancer cells following emetine treatment. Emetine also suppressed the sphere formation of breast cancer cells. These results indicated that emetine may have the potential of inhibiting breast 
A

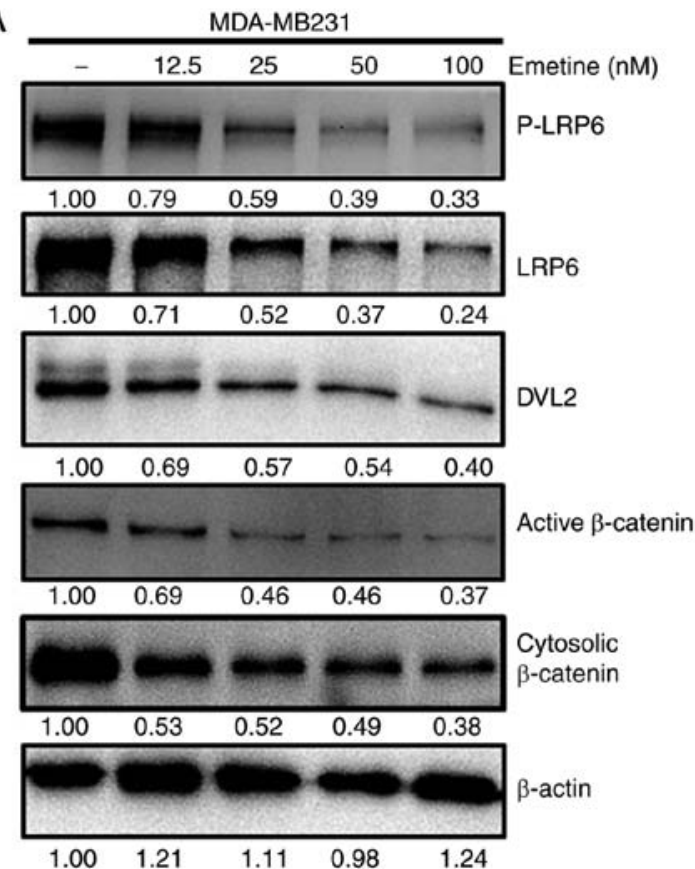

B

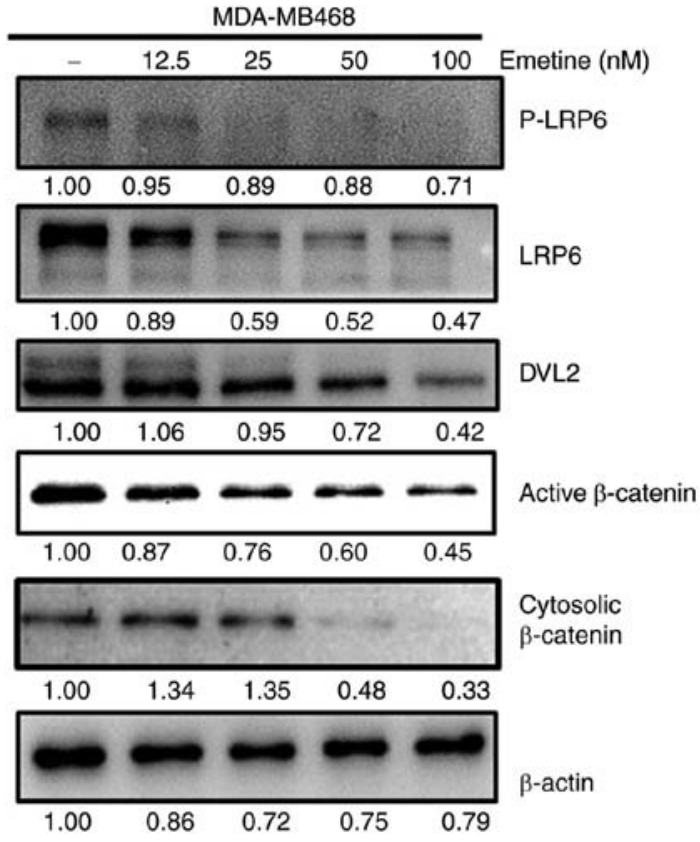

Figure 3. Emetine inhibits the Wnt/ $\beta$-catenin signaling pathway in breast cancer cells. (A) MDA-MB-231 and (B) MDA-MB-468 breast cancer cells were treated with emetine at the indicated concentrations for $24 \mathrm{~h}$. (A and B) The expression levels of phosphorylated LRP6, total LRP6, DVL2, active $\beta$-catenin and total $\beta$-catenin were analyzed by western blotting. A slower-migrating band (upper band) corresponded to phosphorylated DVL2. Western blots were quantitated by densitometry. Each band was presented as corresponding density values normalized to $\beta$-actin signal.
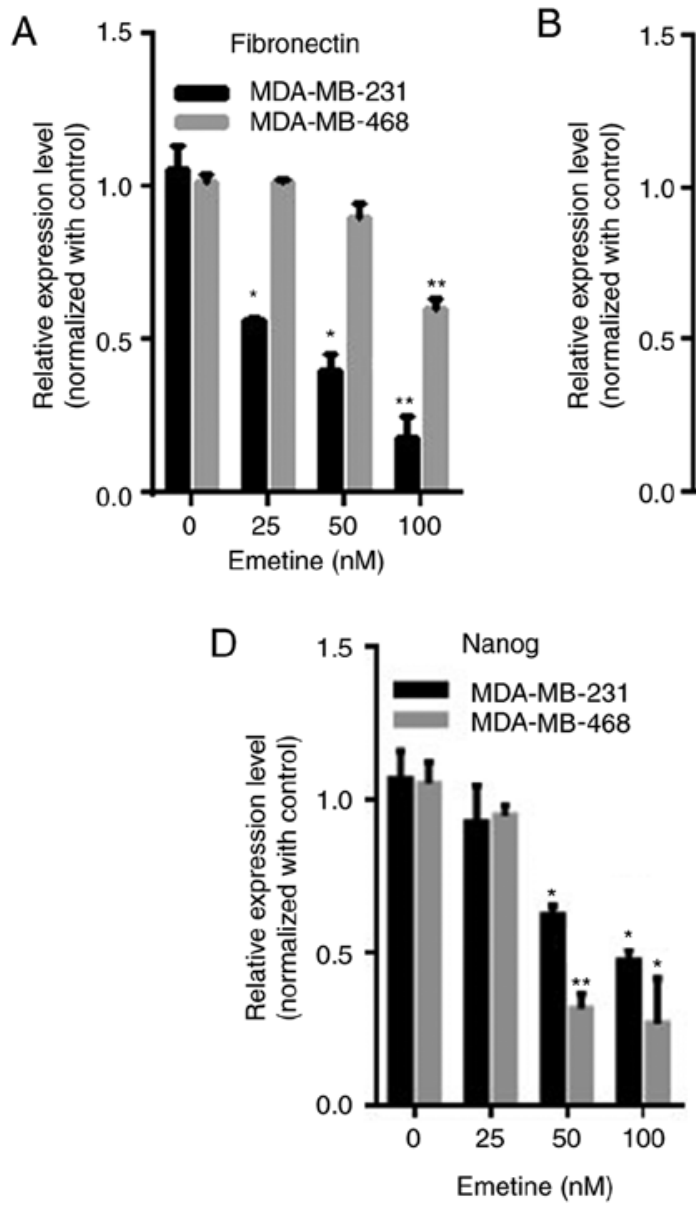
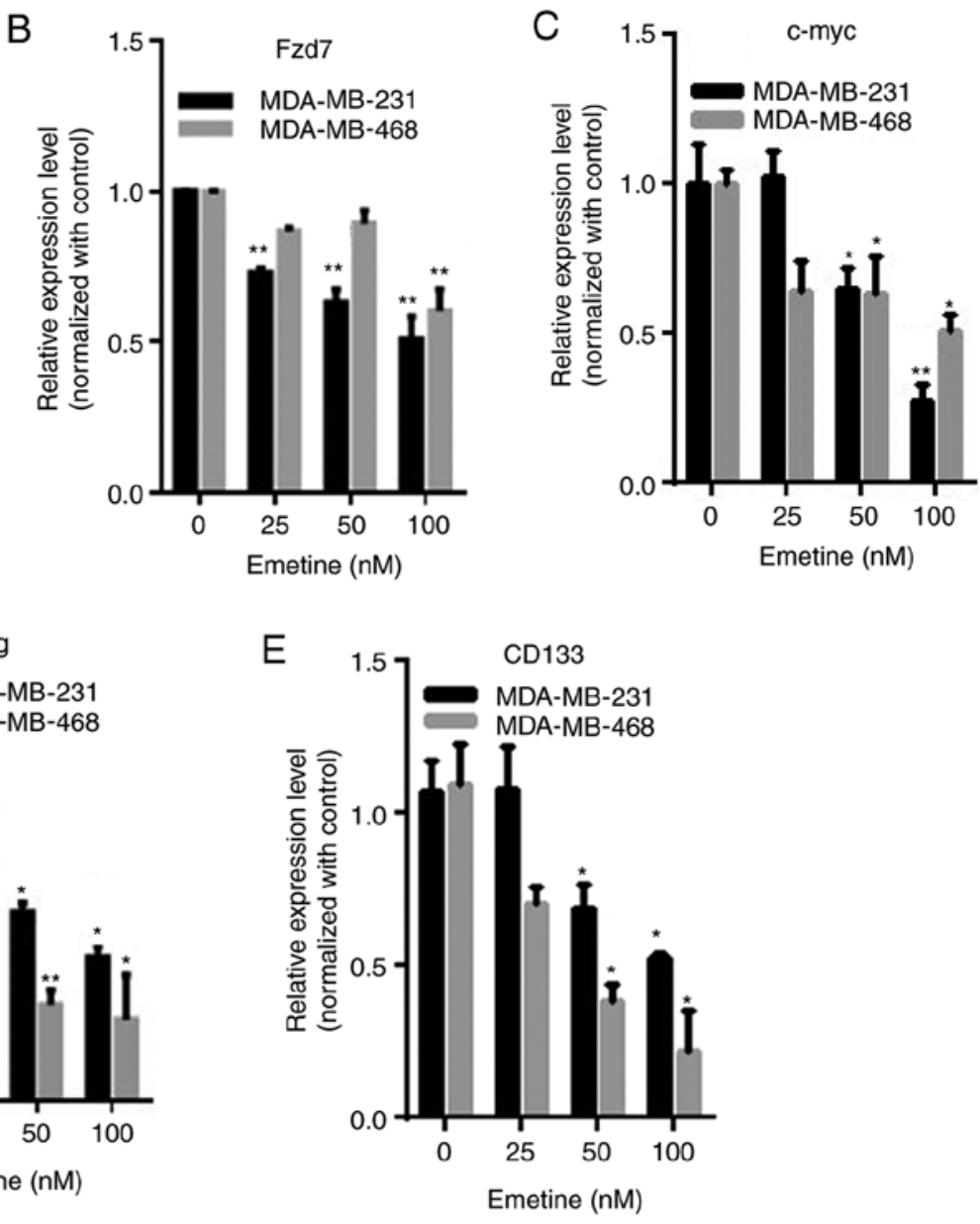

Figure 4. Emetine downregulates Wnt target gene expression in breast cancer cells. MDA-MB-231 and MDA-MB-468 cells were treated with vehicle control (DMSO) or emetine at the indicated concentrations for $24 \mathrm{~h}$ before quantitative PCR analysis to detect the mRNA expression of (A) fibronectin, (B) Fzd7, (C) c-Myc, (D) Nanog and (E) CD133. Data are presented as the mean \pm SD from three independent experiments $\left({ }^{*} \mathrm{P}<0.05,{ }^{* *} \mathrm{P}<0.01\right)$. 

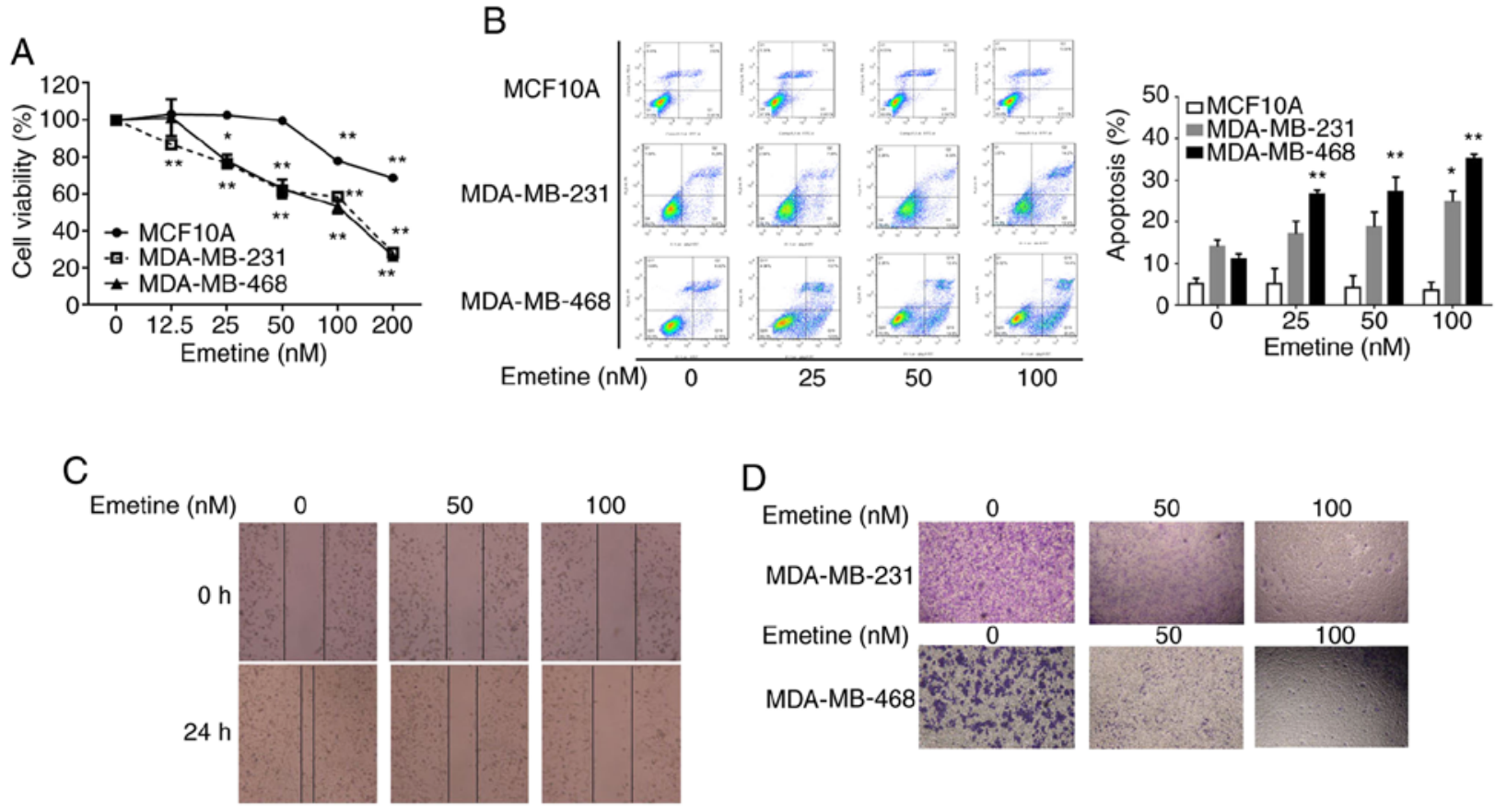

D
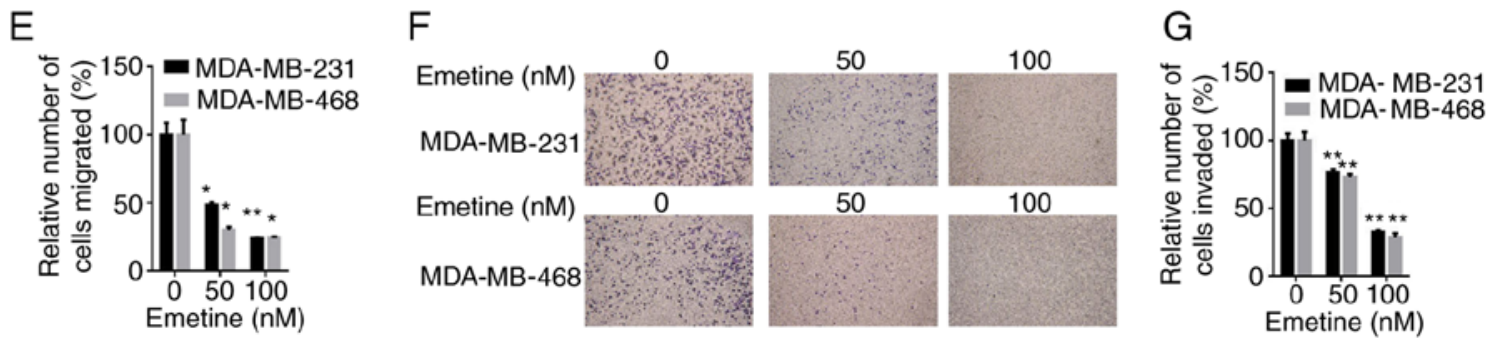

Figure 5. Emetine promotes apoptosis and suppresses viability, migration and invasion in breast cancer cells, but not in MCF10A cells. MDA-MB-231, MDA-MB-468 and MCF10A cells were treated with vehicle control (DMSO) or emetine at the indicated concentrations for $24 \mathrm{~h}$ before evaluation of: (A) cell viability using an MTT assay; (B) apoptosis by FACS; (C) migratory ability in a scratch wound assay; (D) migratory ability in a Transwell assay (upper image, MDA-MB-231 cells; lower image, MDA-MB-468 cells), with quantified data presented in (E); and (F) invasive ability in Matrigel-coated Transwells in the absence or presence of the indicated amounts of emetine for $24 \mathrm{~h}$ (upper image, MDA-MB-231 cells; lower image, MDA-MB-468 cells), with the quantified data presented in (G). Data were collected from three independent experiments ( $\left.\mathrm{P}<0.05,{ }^{* *} \mathrm{P}<0.01\right)$. Statistical analysis was conducted using one-way ANOVA followed by a Dunnett's t-test (A).

cancer stem cells. Collectively, the results of the present study indicated that emetine may be a promising therapeutic agent against breast CSCs. However, further research is required to fully characterize the inhibitory action of emetine on breast CSCs. The CD44+CD24- breast CSCs will be isolated from human breast cancer cell lines and primary breast cancer tissues. Emetine effects on breast CSC activity will be examined using sphere formation assay. The breast CSC xenograft models will be generated by implanting these CD $44^{+} / \mathrm{CD} 24^{-}$breast CSCs. The effect of emetine on the in vivo tumor-seeding ability of breast CSCs will be assessed using breast CSC xenograft mice.

In recent years, derivatives of emetine achieved via structural modifications have also been revealed to have antitumor effects in various cancers (45). For example, novel emetine dithiocarbamate analogs were synthesized and revealed to have anti-tumorigenic activity against prostate cancer cells as well as minimal toxicity to normal prostate cells (46). It will be interesting to assess whether these novel emetine analogs also inhibit the Wnt/ $\beta$-catenin signaling cascade in future studies.

\section{Acknowledgements}

The authors would like to thank the Cancer Research Center, Department of Pharmacology, and Shenzhen University Health Science Center for providing the facilities used to carry out this study.

\section{Funding}

The present study was supported by the National Nature Science Foundation of China (grant no. 81802662), the Nature Science Foundation of Guangdong Province (grant no. 2017A030310329), the Medical Science and Technology Research Foundation of Guangdong Province (grant no. A2019475), the Shenzhen Basic Research Program (grant no. JCYJ20170817094611664), the Shenzhen Peacock Plan (grant nos. 827000183 and 827000186), the Shenzhen Peacock Innovation Team Project (grant no. KQTD20140630100658078), and the Shenzhen University Research Project (grant nos. 2016085 and 2017087). 

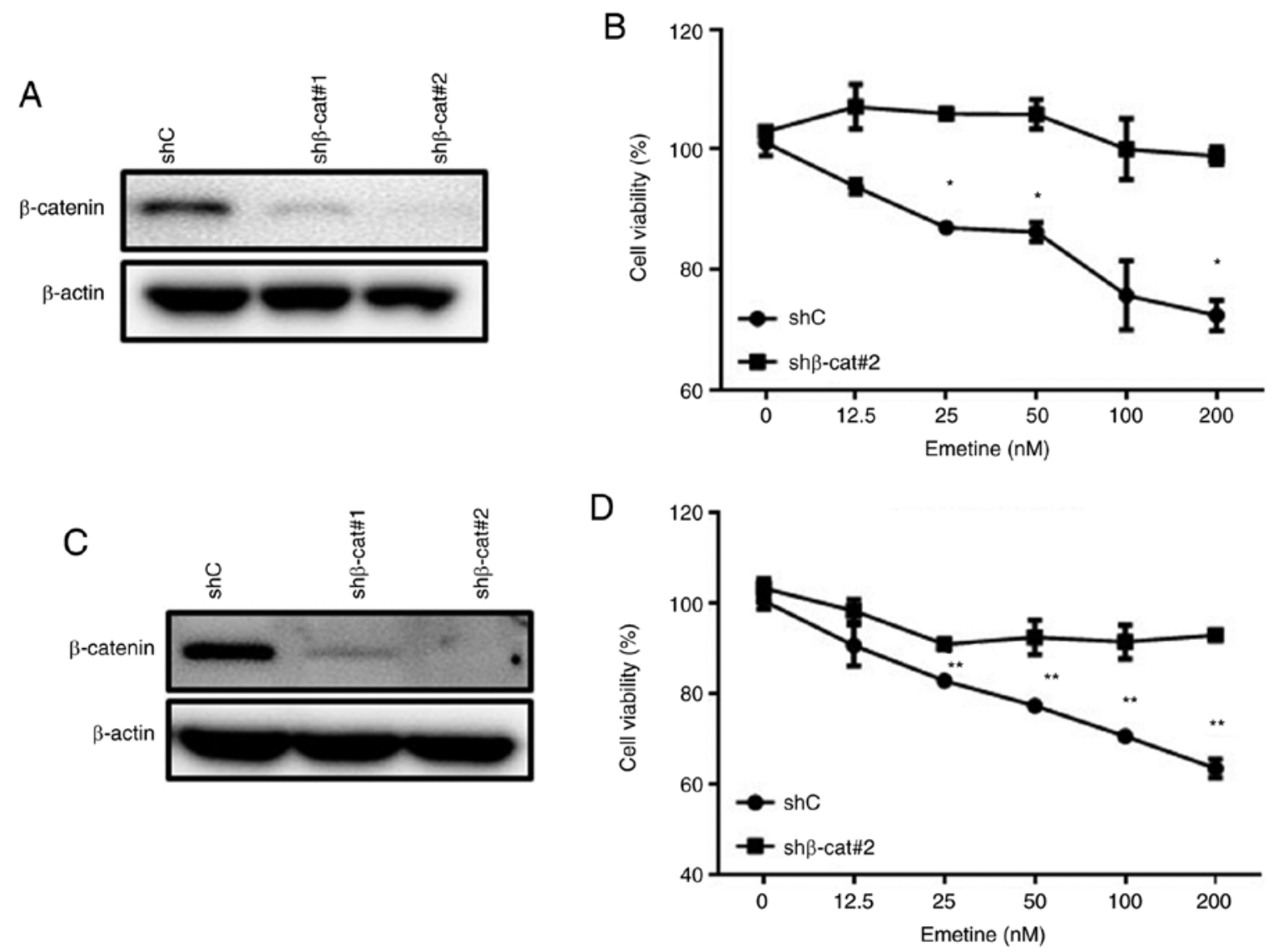

Figure 6. Emetine-induced reduction of cell viability is abrogated by shRNA-mediated silencing of $\beta$-catenin. (A) MDA-MB-231 and (C) MDA-MB-468 cells were infected with lentivirus containing control shRNA $(\operatorname{shC})$ or shRNAs $(\operatorname{sh} \beta$-cat $\# 1, \operatorname{sh} \beta$-cat $\# 2)$ targeting $\beta$-catenin and then treated with DMSO or emetine at the indicated concentration for $24 \mathrm{~h}$, before assessment of (B) MDA-MB-231 and (D) MDA-MB-468 cell viability. Data were collected from three independent experiments $\left({ }^{*} \mathrm{P}<0.05,{ }^{* *} \mathrm{P}<0.01\right)$. Statistical analysis was conducted using one-way analysis of variance (ANOVA) followed by a Dunnett's t-test (B and D).

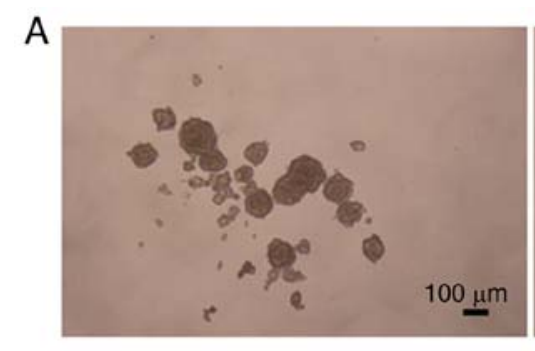

Emetine (nM)

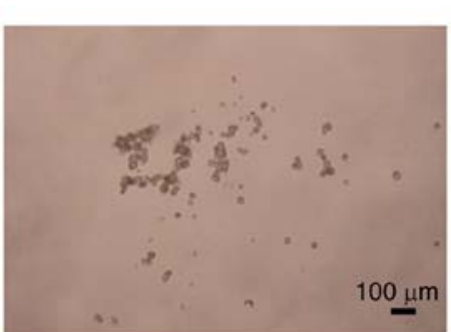

$50 \mathrm{nM}$

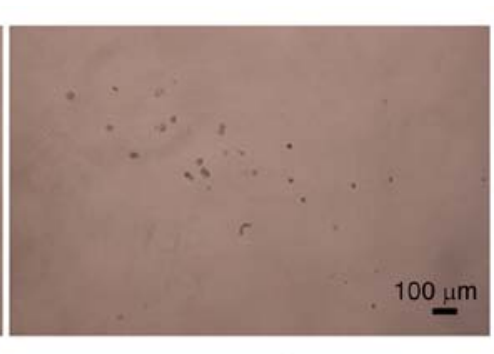

$100 \mathrm{nM}$

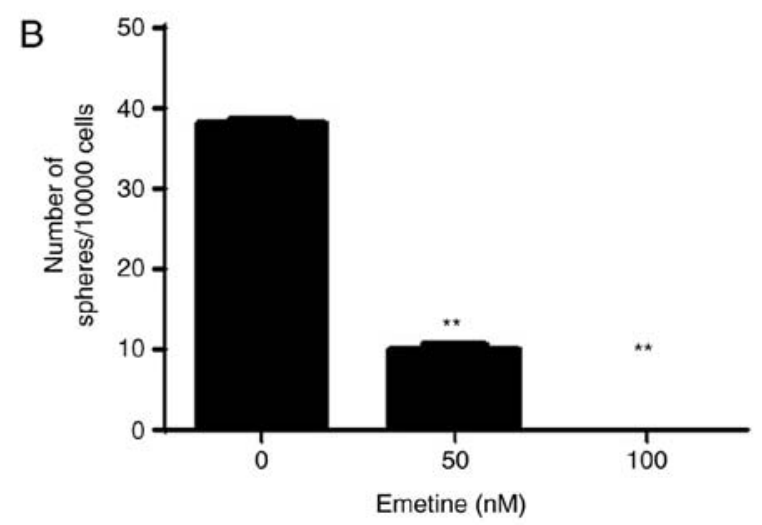

Figure 7. Emetine suppresses the sphere-forming ability of breast cancer cells. (A) Sphere formation of Hs578T cells cultured in Ultra-Low Attachment dishes with or without emetine treatment. Spheres larger than $50 \mu \mathrm{m}$ in diameter were counted under a microscope. Scale bar, $100 \mu \mathrm{m}$. (B) Relative number of spheres formed by Hs578T cells treated with control or emetine at the indicated concentrations. Data are presented as the mean \pm SD from three independent experiments $\left({ }^{* * *} \mathrm{P}<0.01\right)$. 


\section{Availability of data and materials}

Data and materials are available upon request to the corresponding author.

\section{Authors' contributions}

QS performed the research, analyzed the data and wrote the manuscript. QF, SLi, JL and SLiu performed the research. ZW, ZS, JS and DL analyzed and interpreted the data. DL designed the research, analyzed and interpreted the data, and wrote the manuscript. All authors read and approved the manuscript and agree to be accountable for all aspects of the research in ensuring that the accuracy or integrity of any part of the work are appropriately investigated and resolved.

\section{Ethics approval and consent to participate}

Not applicable.

\section{Patient consent for publication}

Not applicable.

\section{Competing interests}

There authors declare that they have no competing interest.

\section{References}

1. Boras-Granic $\mathrm{K}$ and Hamel PA: Wnt-signalling in the embryonic mammary gland. J Mammary Gland Biol Neoplasia 18: 155-163, 2013.

2. Clevers $\mathrm{H}$ : Wnt/beta-catenin signaling in development and disease. Cell 127: 469-480, 2006.

3. Moon RT, Kohn AD, De Ferrari GV and Kaykas A: WNT and beta-catenin signalling: Diseases and therapies. Nat Rev Genet 5 : 691-701, 2004.

4. Pohl SG, Brook N, Agostino M, Arfuso F, Kumar AP and Dharmarajan A: Wnt signaling in triple-negative breast cancer. Oncogenesis 6: e310, 2017.

5. Morgan RG, Ridsdale J, Tonks A and Darley RL: Factors affecting the nuclear localization of $\beta$-catenin in normal and malignant tissue. J Cell Biochem 115: 1351-1361, 2014.

6. Clevers $\mathrm{H}$ and Nusse $\mathrm{R}: \mathrm{Wnt} / \beta$-catenin signaling and disease. Cell 149: 1192-1205, 2012.

7. MacDonald BT and He X: Frizzled and LRP5/6 receptors for Wnt $/ \beta$-catenin signaling. Cold Spring Harb Perspect Biol 4 a007880, 2012 .

8. Wu G, Huang H, Garcia Abreu J and He X: Inhibition of GSK3 phosphorylation of beta-catenin via phosphorylated PPPSPXS motifs of Wnt coreceptor LRP6. PLoS One 4: e4926, 2009.

9. Zeng X, Tamai K, Doble B, Li S, Huang H, Habas R, Okamura H, Woodgett $\mathrm{J}$ and $\mathrm{He} \mathrm{X}$ : A dual-kinase mechanism for Wnt co-receptor phosphorylation and activation. Nature 438: 873-877, 2005.

10. Akinboye ES, Rosen MD, Denmeade SR, Kwabi-Addo B and Bakare O: Design, synthesis, and evaluation of $\mathrm{pH}$-dependent hydrolyzable emetine analogues as treatment for prostate cancer. J Med Chem 55: 7450-7459, 2012.

11. Grollman AP: Inhibitors of protein biosynthesis. V. Effects of emetine on protein and nucleic acid biosynthesis in HeLa cells. J Biol Chem 243: 4089-4094, 1968.

12. Lambert AC: The treatment of amoebic dysentery with emetine and bismuth iodide. Br Med J 1: 116-118, 1918.

13. Kane RC, Cohen MH, Broder LE, Bull MI, Creaven PJ and Fossieck BE Jr: Phase I-II evaluation of emetine (NSC-33669) in the treatment of epidermoid bronchogenic carcinoma. Cancer Chemother Rep 59: 1171-1172, 1975.
14. Mastrangelo MJ, Grage TB, Bellet RE and Weiss AJ: A phase I study of emetine hydrochloride (NSC 33669) in solid tumors. Cancer 31: 1170-1175, 1973.

15. Panettiere F and Coltman CA Jr: Experience with emetine hydrochloride (NSC 33669) as an antitumor agent. Cancer 27: 835-841, 1971.

16. Siddiqui S, Firat D and Olshin S: Phase II study of emetine (NSC-33669) in the treatment of solid tumors. Cancer Chemother Rep 57: 423-428, 1973.

17. Akinboye ES, Bamji ZD, Kwabi-Addo B, Ejeh D, Copeland RL, Denmeade SR and Bakare O: Design, synthesis and cytotoxicity studies of dithiocarbamate ester derivatives of emetine in prostate cancer cell lines. Bioorg Med Chem 23: 5839-5845, 2015.

18. Akinboye ES, Rosen MD, Bakare O and Denmeade SR: Anticancer activities of emetine prodrugs that are proteolytically activated by the prostate specific antigen (PSA) and evaluation of in vivo toxicity of emetine derivatives. Bioorg Med Chem 25: 6707-6717, 2017.

19. Bicknell GR, Snowden RT and Cohen GM: Formation of high molecular mass DNA fragments is a marker of apoptosis in the human leukaemic cell line, U937. J Cell Sci 107: 2483-2489, 1994.

20. Moller M, Weiss J and Wink M: Reduction of cytotoxicity of the alkaloid emetine through P-glycoprotein (MDR1/ABCB1) in human Caco-2 cells and leukemia cell lines. Planta Med 72: 1121-1126, 2006

21. Moller M and Wink M: Characteristics of apoptosis induction by the alkaloid emetine in human tumour cell lines. Planta Med 73: 1389-1396, 2007.

22. Rosenkranz V and Wink M: Alkaloids induce programmed cell death in bloodstream forms of trypanosomes (Trypanosoma $b$. brucei). Molecules 13: 2462-2473, 2008.

23. Watanabe N, Iwamoto T, Dickinson DA, Iles KE and Forman HJ: Activation of the mitochondrial caspase cascade in the absence of protein synthesis does not require c-Jun N-terminal kinase. Arch Biochem Biophys 405: 231-240, 2002.

24. Kong HS, Lee S, Beebe K, Scroggins B, Gupta G, Lee MJ, Jung YJ, Trepel $\mathbf{J}$ and Neckers L: Emetine promotes von Hippel-Lindau-independent degradation of hypoxia-inducible factor- $2 \alpha$ in clear cell renal carcinoma. Mol Pharmacol 78: 1072-1078, 2010

25. Foreman KE, Jesse JN III, Kuo PC and Gupta GN: Emetine dihydrochloride: A novel therapy for bladder cancer. J Urol 191: 502-509, 2014.

26. Sun Q, Yogosawa S, Iizumi Y, Sakai T and Sowa Y: The alkaloid emetine sensitizes ovarian carcinoma cells to cisplatin through downregulation of bcl-xL. Int J Oncol 46: 389-394, 2015.

27. Visnyei K, Onodera H, Damoiseaux R, Saigusa K, Petrosyan S, De Vries D, Ferrari D, Saxe J, Panosyan EH, Masterman-Smith M, et al: A molecular screening approach to identify and characterize inhibitors of glioblastoma stem cells Mol Cancer Ther 10: 1818-1828, 2011.

28. Mayank and Jaitak V: Molecular docking study of natural alkaloids as multi-targeted hedgehog pathway inhibitors in cancer stem cell therapy. Comput Biol Chem 62: 145-154, 2016.

29. Lu D, Choi MY, Yu J, Castro JE, Kipps TJ and Carson DA: Salinomycin inhibits Wnt signaling and selectively induces apoptosis in chronic lymphocytic leukemia cells. Proc Natl Acad Sci USA 108: 13253-13257, 2011

30. Lu D, Zhao Y, Tawatao R, Cottam HB, Sen M, Leoni LM, Kipps TJ, Corr M and Carson DA: Activation of the Wnt signaling pathway in chronic lymphocytic leukemia. Proc Natl Acad Sci USA 101: 3118-3123, 2004.

31. Mandal CC, Ghosh-Choudhury N, Yoneda T, Choudhury GG and Ghosh-Choudhury N: Simvastatin prevents skeletal metastasis of breast cancer by an antagonistic interplay between p53 and CD44. J Biol Chem 286: 11314-11327, 2011.

32. Vlckova L, Vondrejs V and Necasek J: The interaction of emetine with DNA and its effect on the adsorption of certain bacteriophages. Folia Microbiol. (Praha) 15: 76-81, 1970.

33. Aoki T, Shimada K, Sakamoto A, Sugimoto K, Morishita T, Kojima Y, Shimada S, Kato S, Iriyama C, Kuno S, et al: Emetine elicits apoptosis of intractable B-cell lymphoma cells with MYC rearrangement through inhibition of glycolytic metabolism. Oncotarget 8: 13085-13098, 2017.

34. Zhou YD, Kim YP, Mohammed KA, Jones DK, Muhammad I, Dunbar DC and Nagle DG: Terpenoid tetrahydroisoquinoline alkaloids emetine, klugine, and isocephaeline inhibit the activation of hypoxia-inducible factor-1 in breast tumor cells. J Nat Prod 68: 947-950, 2005. 
35. Milovanovic T, Planutis K, Nguyen A, Marsh JL, Lin F, Hope C and Holcombe RF: Expression of Wnt genes and frizzled 1 and 2 receptors in normal breast epithelium and infiltrating breast carcinoma. Int J Oncol 25: 1337-1342, 2004.

36. Benhaj K, Akcali KC and Ozturk M: Redundant expression of canonical Wnt ligands in human breast cancer cell lines. Oncol Rep 15: 701-707, 2006.

37. King TD, Suto MJ and Li Y: The Wnt/ $\beta$-catenin signaling pathway: A potential therapeutic target in the treatment of triple negative breast cancer. J Cell Biochem 113: 13-18, 2012.

38. Nagahata T, Shimada T, Harada A, Nagai H, Onda M, Yokoyama S, Shiba T, Jin E, Kawanami O and Emi M: Amplification, up-regulation and over-expression of DVL-1, the human counterpart of the Drosophila disheveled gene, in primary breast cancers. Cancer Sci 94: 515-518, 2003.

39. Schlange T, Matsuda Y, Lienhard S, Huber A and Hynes NE: Autocrine WNT signaling contributes to breast cancer cell proliferation via the canonical WNT pathway and EGFR transactivation. Breast Cancer Res 9: R63, 2007.

40. Dawood S, Austin L and Cristofanilli M: Cancer stem cells: Implications for cancer therapy. Oncology (Williston Park) 28: 1101-1107, 1110, 2014.

41. Holland JD, Klaus A, Garratt AN and Birchmeier W: Wnt signaling in stem and cancer stem cells. Curr Opin Cell Biol 25: 254-264, 2013.
42. Horst D, Kriegl L, Engel J, Jung A and Kirchner T: CD133 and nuclear beta-catenin: The marker combination to detect high risk cases of low stage colorectal cancer. Eur J Cancer 45: 2034-2040, 2009.

43. Ibrahim EE, Babaei-Jadidi R, Saadeddin A, Spencer-Dene B, Hossaini S, Abuzinadah M, Li N, Fadhil W, Ilyas M, Bonnet D and Nateri AS: Embryonic NANOG activity defines colorectal cancer stem cells and modulates through AP1- and TCF-dependent mechanisms. Stem Cells 30: 2076-2087, 2012.

44. Iv Santaliz-Ruiz LE, Xie X, Old M, Teknos TN and Pan Q: Emerging role of nanog in tumorigenesis and cancer stem cells. Int J Cancer 135: 2741-2748, 2014.

45. Uzor PF: Recent developments on potential new applications of emetine as anti-cancer agent. EXCLI J 15: 323-328, 2016.

46. Bamji ZD, Washington KN, Akinboye E, Bakare O, Kanaan YM and Copeland RL Jr: Apoptotic effects of novel dithiocarbamate analogs of emetine in prostate cancer cell lines. Anticancer Res 35: 4723-4732, 2015.

(i) (2) This work is licensed under a Creative Common Attribution-NonCommercial-NoDerivatives 4.0 International (CC BY-NC-ND 4.0) License. 